Mapping stands in Northern New Brunswick indicates that extensive areas are currently susceptible to budworm infestation. Management of the forest in the past 25 years has not reduced the susceptibility to attack, concludes G. D. VAN RAALTE ${ }^{1}$. Foresters from Ontario to Nova Scotia should find out here what are the characteristics of susceptible stands and ask themselves

\title{
"Do I have a budworm-susceptible forest?"
}

${ }^{1}$ Maritimes Forest Research Centre, Canadian Forestry Service,

Fredericton, New Brunswick.

La cartographie des peuplements situés dans le nord du Nouveau-Brunswick montre que de larges superficies sont souvent sujettes aux infections de la tordeuse. L'aménagement de la forêt des dernières 25 années n'a pas réduit la susceptibilité à ces attaques. Les ingénieurs forestiers de l'Ontario jusqu'à la Nouvelle-Ecosse devraient trouver dans le présent article les critères de cette susceptibilité et examiner les peuplements dans leurs propres régions.

Forest managers, as well as ecologists concerned with the forest ecosystem, generally agree that the management of spruce budworm (Choristoneura fuminifera Clem.) populations would be desirable by means other than the large scale aerial spraying at the peak of an outbreak. The most obvious alternatives is to prevent populations from ever reaching outbreak proportions. This idea was considered by Tothill (1923) and Swaine and Craighead (1924). when they observed severe mortality in overmature softwood stands after the 1912-1920 outbreak in New Brunswick. They saw the necessity of managing these stands in order to manage the budworm. The idea of managing the forest to protect it against the budworm was enlarged by Balch (1946) who stated that: "If the danger of future infestations and damage by the spruce budworm in the Maritime Region is to be reduced by management, it is desirable to obtain a general picture of the nature of the forest and its relative susceptibility to budworm attack".

Balch examined aerial photographs of New Brunswick and classified the stand at the centre of each photo with respect to susceptibility based on size and density of the softwood component (Fig. 1). The area of high hazard in northern Victoria, Restigouche, and Madawaska counties defined by Balch corresponds closely to the actual area of moderate to severe budworm infestation in 1952 (Webb et al. 1961), suggesting that this type of mapping is both accurate and useful (Fig. 2). I report here on a similar mapping exercise carried out in Madawaska, Victoria, and Restigouche counties in 1970. While this task was undertaken as part of a comprehensive budworm study, it has resulted in a map showing that susceptible forests in this area are extensive (Fig. 3).

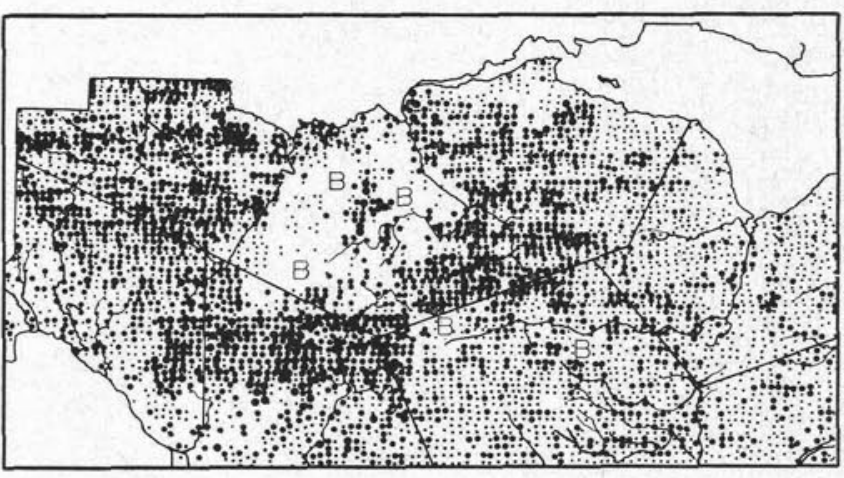

Fig. 1. A reproduction of the northern New Brunswick portion of Balch's budworm susceptibility map (1946). The three dot sizes refer to low, moderate, and highly susceptible. B denotes a large burn area.

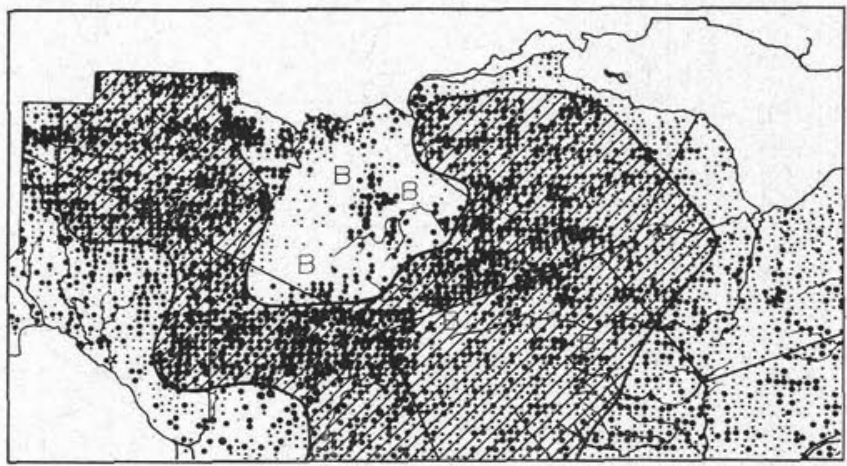

Fig. 2. An outline of the area of budworm infestation in 1952 (the first year of aerial spraying) superimposed on Balch's susceptibility map.

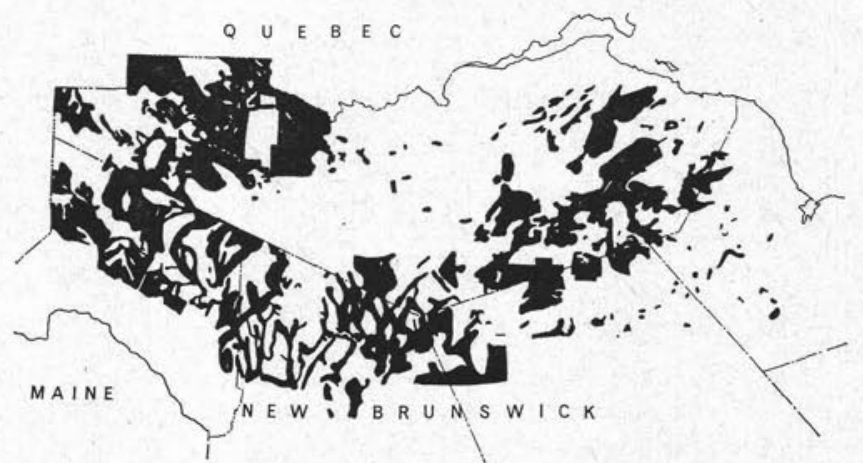

Fig. 3. A balsam fir continuity map of northern New Brunswick. 
The problem

The temporary nature of the protection achieved by spraying, coupled with the fact of burgeoning infestations in eastern North America, emphasizes the need for alternative strategies in budworm management. In attempting to frame these strategies, a central issue is the theory that forests have varying degrees of susceptibility to budworm. This theory may be stated as follows: Under favorable macroclimate conditions, outbreaks develop in discrete areas, known as epicenters, that have a number of attributes (food quantity and quality, stand climate, etc.) that favor high budworm survival and a release from the normal biocontrols resulting in a population explosion. These local points rapidly coalesce through small-larval and moth dispersal to produce a widespread budworm epidemic.

The central question is: Do epicenters, as defined above, exist and, if so, can they be recognized and identified in advance of an outbreak? A major study involving several investigators is attempting to answer this question. To facilitate this study, it was necessary to identify the forest types most likely to contain epicenters. The simplest way of approaching this identification was to assume that forests most susceptible to budworm infestation would contain within them the stands most likely to be epicenters. On this assumption, a first step in the epicenter study was to identify on maps the susceptible forest over an extensive area in northern New Brunswick. The mapping was carried out using criteria based on observations by Swaine and Craighead (1924), Balch (1946), and Morris and Bishop (1951) as well as by the current budworm investigation team. These criteria are:

\section{1/ Species composition:}

- Fir-spruce stands are highly susceptible if $50 \%$ or more (by volume) is balsam fir (Abies balsamea (L.) Mill.) and the associated species is white spruce (Picea glauca (Moench) Voss) or red spruce (P. rubens Sarg.).

- Susceptibility decreases with decreasing fir content.

- Susceptibility decreases if fir is associated with black spruce (P. mariana (Mill.) BSP.) or other non-host species.

2/ Stand age-height:

- Susceptibility is increased if conifers are older than 60 years.

- Stands are generally non-susceptible if conifers are less than 40 years.

- Potentially vulnerable stands are less susceptible if overtopped by non-host species.

3/ Stand density:

- Susceptibility is greatly increased where conifers average more than 8 cords/acre and crown closure reaches a maximum.

4/ Isolation:

- Susceptibility is greatly increased where stands are within a continuous forest which is, in general, susceptible.

- Isolated stands of 100 acres or less are nonsusceptible.

5/ Topography:

- The influence of topography on susceptibility is not well-understood but it is clear that altitude, slope, and aspect combine to create local climates which yield either favorable or unfavorable environments for budworm development.

A trial

The five basic criteria of susceptibility were evaluated by 13 ecological parameters associated with budworm development (Table 1). Using these parameters, susceptibility was evaluated on a large

TABLE 1. Relationship between budworm behavior and surfival, and forest parameters measured in the survey

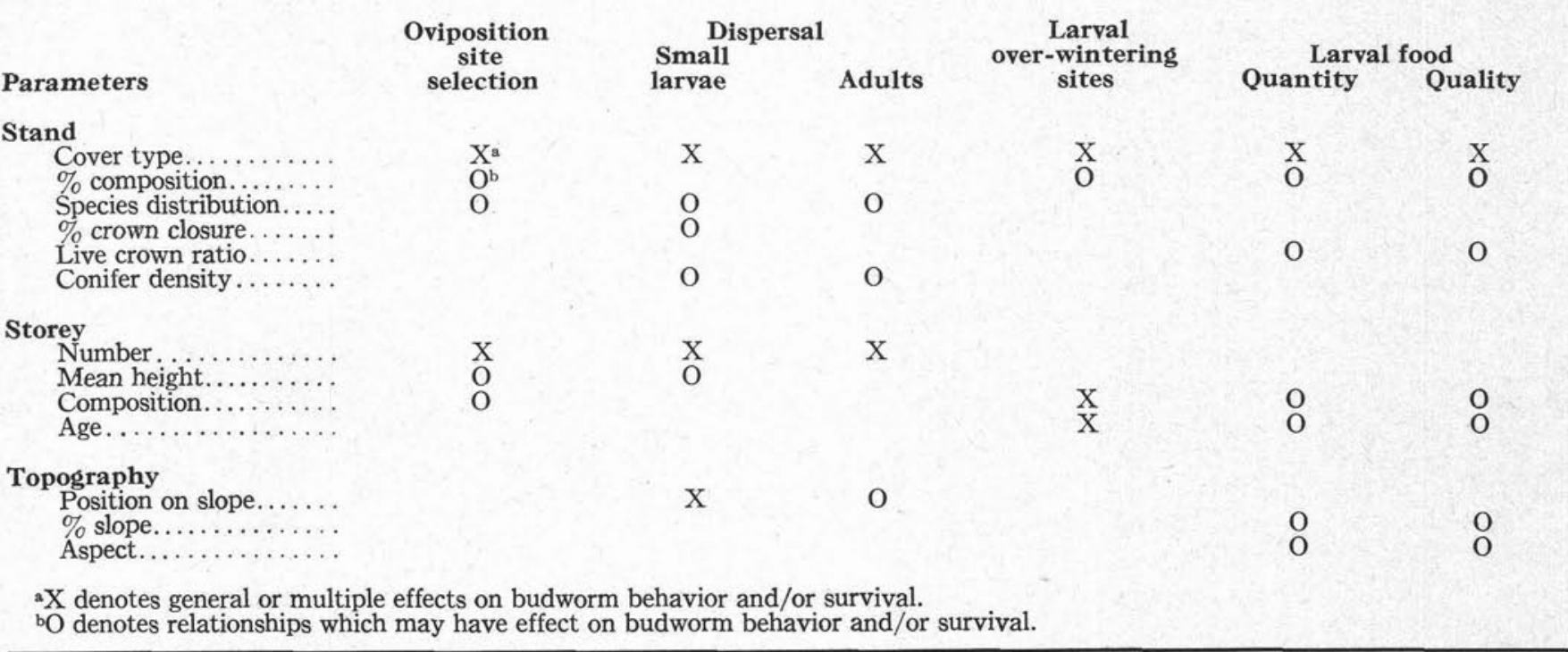


area (about 6,500 square miles) using largely qualitative assessments. Only basal area, species composition, tree height, slope, and aspect were measured quantitatively.

Northern New Brunswick was chosen as the study area because the budworm population has been at an endemic level in that region since 1959 and the region provides a wide range of forest and local climate conditions. Background information on budworm population trends, stand development, and productivity was also available from the Green River Project. The low budworm population (endemic level 30 small larvae/tree versus 20,000 at the peak of an epidemic) was a critical factor in selecting the study area because once susceptibility is mapped, it is intended that subsequent studies will examine the variation in population survival across the range of susceptibility parameters.

The survey was conducted using base maps (20 chains/inch) coupled with aerial photos to locate stands across the full range of stand conditions with respect to budworm susceptibility. Sampling was restricted to broad forest types known to be susceptible to infestation. Sample points were determined by photo-interpretation, marked on aerial photos, and located and checked in the field before they were accepted as representative of the stand as a whole. Data for each sample point were coded for sorting and tabulating. Since the object of the sampling was to get a preliminary ecological characterization of stands across the range of susceptibility, the use of cover-type maps was precluded except for preliminary identification of stands.

A total of 4,440 square miles were scanned in the survey and 410 stands were sampled. The distribution of sample points among cover types was as follows: $67 \%$ were located in stands with $75 \%$ or more softwood by volume; $28 \%$ in stands with $50-74 \%$ softwood by volume; and $5 \%$ in stands with $25-49 \%$ softwood by volume. The distribution of the sample points shows a distinct, and intentional, bias towards the pure softwood cover-type as a result of the assumption that a pure softwood stand is more budworm-prone than a mixedwood stand.

To place some perspective on the data gathered, and to make the location of permanent sample plots for other studies in the epicenter approach easier, a balsam fir continuity map was produced using the three most frequently encountered parameters (Fig. 3 ). This map shows the approximate location of stands greater than 400 acres in which the balsam fir content exceeds $50 \%$ of the volume, the average height of the fir component is greater than 30 feet, and the average age greater than 35 years. The continuity map provides a reasonable picture of fir stands that are currently vulnerable to damage if not to a population explosion. Of the 4,440 square miles covered, $41 \%$ meet these conditions. Eventually maps of budworms egg density or budworm larval density will be superimposed on this map to further our understanding of budworm abundance in relation to forest type and topographic position.
Finally, it is of interest to compare the present map with the one drawn by Balch in 1946. It appears that extensive budworm-prone forests in 1970 remain in roughly the same locations as in 1946 in the northern part of the province, in spite of the cutting which has taken place in the intervening years. Complete data are not available to indicate the rate at which cutting may be "defusing" these budworm-prone forests; however, an indication may be obtained. In one large watershed in the study area, for example, net merchantable increment for spruce and fir is estimated to be $38.0 \mathrm{ft}^{3} /$ acre per year. The average cut on the same watershed for the period 1966-71 was $28 \mathrm{ft}^{3} /$ acre per year. Thus, in this part of the area, growth still exceeds the cut by $10 \mathrm{ft}^{3} /$ acre per year. Much of the growth is on extensive areas where the stands were destroyed or seriously damaged by the 1912-20 budworm outbreak and now largely occupied by budworm-prone forests.

\section{Conclusion}

The forest area covered by this preliminary survey has a wide range of stand types and conditions. The techniques used have identified the susceptible parts of this forest and, if the original assumption that the susceptible forest contains the potential epicenters is correct, the present mapping should provide a reasonable framework for more intensive sampling associated with the larger comprehensive study. In the meantime, it is clear from this exercise that extensive areas of northern New Brunswick are currently susceptible to budworm infestation. In fact, the situation is little different from that reported by Balch in 1946 when he warned of the danger of imminent outbreak. It must be concluded that, in the intervening 25 years, management of the forest in northern New Brunswick has not resulted in any reduction in their susceptibility to spruce budworm attack.

\section{Acknowledgement}

This study was supported by Forest Protection Limited.

\section{References}

BALCH, R. E. 1946. The spruce budworm and forest management in the Maritime Provinces. Can. Dep. Agr., Entomol. Div., Proc. Publ. 60.

MORRIS, R. F. and R. L. BISHOP. 1951. A method of rapid forest survey for mapping vulnerability to spruce budworm damage. Forest. Chron. 27: 171-178.

SWAINE, J. M. and F. C. CRAIGHEAD. 1924. Studies on the spruce budworm (Cacoecia fumiferana Clem.). Can. Dep. Agr., Bull. 37 n.s.

TOTHILL, J. D. 1923. Notes on the outbreak of spruce budworm, forest tent caterpillar and larch sawfly in New Brunswick. Acadian Entomol. Soc., Proc. 8 (1922): 172182.

WEBB, F. E., J. R. BLAIS and R. W. NASH. 1961. A cartographic history of spruce budworm outbreaks and aerial forest spraying in the Atlantic region of North America, 1949-1959. Can. Entomol. 93: 360-379. 